\title{
An Analysis of Iranian Electronic Cities Case Study: Uremia City (Challenges and Opportunities) ${ }^{1}$
}

\author{
Jabbar Alizadeh ASL (Corresponding Author)
}

Ph.D. Student of Geography and Urban Planning, University of Isfahan, Iran

Tel: 98-914-201-7984Ｅ-mail: alizadehali91@yahoo.com

\author{
Dr. Asghar Zarrabi \\ Professor of Geography and Urban Planning Department, University of Isfahan, Iran \\ E-mail: a.zarabi@geo.ui.ac.ir \\ Dr. Masoud Taghvaei \\ Professor of Geography and Urban Planning Department, University of Isfahan, Iran \\ E-mail: m.taghvaei@geo.ui.ac.ir
}

Received: April 26, 2015 Accepted: May 10, 2015

doi:10.5296/emsd.v4i2.7496 URL: http://dx.doi.org/10.5296/emsd.v4i2.7496

\begin{abstract}
Electronic cities result from the implication of information and communication technology (ICT) in the contemporary era. Significant ICT development and internet network expansion as well as the need of urban management to new ideas in managing cities lead us toward a new strategy called "electronic cities". The current study aims at investigating the strategic planning of Iranian electronic cities, case study of the metropolitan uremia, Iran. Research method is documentary and survey. Research Statistical population consists of all experts located in Uremia, selected through Morgan Table. To collect data, Likert spectrum is employed. Findings indicate that the most important challenges in the way of establishing an electronic city include the lack of strategic document for urban development, high number of decision-making centers and administrative extra parallel works among them, the inclination of the urban managers toward traditional methods, low-speed, high-cost internet connection, the lack of infrastructures for ICT, the lack of digital literacy among citizens and so on.
\end{abstract}

\footnotetext{
1 - This paper has been extracted from $\mathrm{PhD}$ dissertation
} 
According to the findings, some strategies have been recommended, which they need the serious care of urban managers and planners in the metropolitan Uremia.

Keywords: Strategic Planning, Electronic Planning, Electronic City, the Metropolitan Uremia, SWOT Model.

\section{Introduction}

\subsection{Statement of the Problem}

The twentieth century witnessed the rapid urbanization of the world's population. The global Proportion of urban population increased from a mere13 per cent in 1900 to 29 per cent in 1950 and, according to the 2005 Revision of World Urbanization Prospects, reached 49 per cent in 2005. Since the world is projected to continue to urbanize, 60 per cent of the global population is expected to live in cities by 2030 . The rising numbers of urban dwellers give the best indication of the scale of these unprecedented trends: the urban population increased from 220 million in 1900 to 732 million in 1950, and is estimated to have reached 3.2 billion in 2005, thus more than quadrupling since 1950. According to the latest United Nations population projections, 4.9 billion people are expected to be urban dwellers in 2030 (United Nations, 2006). By 2010, 12 of the 21 mega-cities in the world are expected to be in Asia. Tokyo, the largest, is projected to have a population of 35.4 million, followed by Mumbai (20.0 million), Delhi (16.9), Shanghai (15.7), Kolkata (15.5), Jakarta (15.2), Dhaka (14.6), Karachi (13.2), Manila (11.7), Beijing (11.7), Osaka-Kobe (11.3), and Istanbul (10.5). By 2015, Guangzhou with a population of 10.4 million may qualify as a mega-city. Not too far behind are nine other Asian cities with large populations including Seoul (9.5 million), Shenzhen (8.9), Lahore (8.3), Wuhan (8.2), Tianjin (8.1), Bangalore (7.9), Hong Kong (7.8), Bangkok (7.4) and Hyderabad (7.4) (United Nations, 2008). Urbanization is progressing rapidly in the less developed regions and urban population is anticipated to grow an average $2.3 \%$ per year in the developing world between 2000 and 2030 (Chen, Jie. 2007). Since 2008, more than half of the world's population is living in urban areas. The number of urban residents is expected to continue to grow, especially in developing countries. In Asia some 1.1 billion are anticipated to move to cities in the next 20 years (Tai-Chee Wong et al, 2011).

According to Statistical Year Book, Iran 2011, nearly 75 per cent of Iranian population lives in urban regions (Statistical Year Book 2011). Therefore, Iranian cities such as Tehran, Isfahan, Tabriz, Mashhad and Uremia, to name few, face such challenges and problems as unequal access to services (Zarrabi, A. et al, 2010), social inequality in passing leisure times (Sadeghi, R. et al, 2010), income and education inequalities (Yusefi, A. et al, 2011), queues in access to services (Varesi, H. et al, 2011), lack of citizens' participation in urban management (Shiyani, M. et al, 2012), urban traffic congestion (Alipoor, M. A., 2003), lack of efficient public transportation systems (Ahadi, H. R. et al, 2013), lack of safety in urban neighborhoods (Rezwan, A. et al, 2012), lack of paying due attention to the rights of people with disabilities and target groups in the access to services (Safdarzadeh, Z. 2013), ecological pollutions (Sadeghi, H. et al, 2004), carbon economy (Bakhtiari, S. et al, 2013), low life quality, centralization, corruption and bureaucracy (Zahedi, Sh. et al, 2009), approximately 8 million of urban dwellers in Slums and so on (Ladan, A. et al, 2009). 
The establishment of electronic cities ${ }^{2}$ is considered among the scenarios proposed for solving above-mentioned challenges in the contemporary literature of the urban planning (Alizadeh, J. et al, 2014; Zarrabi, A. et al, 2011; Mohammadi, J. et al, 2013; Taghvaei, M. et al, 2010). Apparently, in the contemporary era, urban management may not be carried out based on traditional methods because not paying attention to this point entails not only wasting natural and human resources, but also lowering the life quality of the citizens. Therefore, the current study makes efforts to investigate the challenges and opportunities in the face of the Metropolitan Uremia regarding the establishment of an electronic city.

\subsection{Significance of Study}

Urban planning has experienced numerous changes over its long history. However, from the viewpoint of urban planners and other stakeholders, none of those changes has made such methodological revolution as using ICT in all stages of planning process. Electronic planning (E-planning) refers to a new planning paradigm. In this type of planning, ICT, especially internet, Geography Information System (GIS) and virtual reality technologies have widely assisted urban mangers, planners and other stakeholders (Silva, Carlos Nunes, 2010). Although ICT may be seen as neutral technologies, it can be actually employed for targeting different socio-political goals or responding to different values and principles. Therefore, using ICT seeks different goals in rational planning approach in comparison to communicational planning. In the first glance, ICT foundations allow planners and planning departments to improve conventional decision-making processes for either carrying out new initiatives or implementing conventional methods through new tools such as GIS, virtual reality technologies, electronic participation tools, etc. In the second stage, using ICT seems as inclination toward epistemological turn and change in the pattern of planning. It is beyond the fundamental goal of common improvement in planning. Better planning and more efficient urban management services with lower costs as well as collaborative, participative, transparent and accountable planning are considered as informed decision-making about fundamental goals of e-planning, requiring the move from conventional urban planning to electronic one (Silva, Carlos Nunes, 2010). Therefore, it is not surprising to say that cities in developing countries need a new approach in urban development literature more than those in developed countries in order to reduce negative consequences of urbanization development because they suffer more from a paradox resulted from planning nature than their counterparts in the developed countries (Hosseinzadeh Delir et al, 2011) in such a manner that developers, politicians and citizens, all and all, believe in planning tradition as a main cause of disorders occur in urban societies (Hanley, Daniel, 2003). The present study is significant from the viewpoint that there is no research carried comprehensively out concerning the strategic planning of Iranian electronic cities. Therefore, it attempts to cover the above-mentioned important point in the Metropolitan Uremia.

\footnotetext{
2 Electronic city refers to such different concepts as (invisible city, Batty, 1990) ‘(informational city, Castells, 1989 ،( )weak metropolis, Dematteis, 1988), (wired city, Dutton et al.,1987) ‘(telicity, Fathy, 1991) ‘(city in the electronic age, Harris, 1987), (information city, Hepworth, 1987) ‘(knowledge-based city, Knight, 1989) ‘(intelligent city, Latterasse, 1992 ، )Virtual city, Martin, 1978), (Electronic communities, Poster, 1990), (Communities without boundaries, Pool, 1980), (Electronic cottage, Toffler, 1981) ،(Electronic spaces, Robins and Hepworth, 1988), all of which mean the use of ICT in all aspects of human daily lives. For more details, see "Telecommunications and the City" written by Stephen Graham and Simon Marvin (1996).
} 
1.3 Research Purpose

In the current research, efforts are made to evaluate threats and opportunities in the face of the possibility of electronic city establishment in Uremia, Iran.

\subsection{Research Question}

Which strategy is required for the establishment of electronic city in Uremia?

\subsection{Materials and Methods}

The present study is of descriptive-analytical nature. To collect data, documentary investigation, library research and field studies have been done. According to gathered data, strengths, weaknesses, threats and opportunities of the possibility of electronic city establishment in Uremia has been investigated. To analyze data, SWOT model has been employed. For so doing, Uremia's external environment (strengths and weaknesses) and internal environment (threats and opportunities) have been investigated and required data has been gathered from senior urban managers, specialists and ICT experts through questionnaires. Then, SWOT matrix has been competed through assigning weights to the elements. Ultimately, proper strategies have been recommended for the establishment of electronic city in Uremia.

\subsection{Study Area}

As one of the Iranian metropolitans, Uremia is the capital of West Azerbaijan province. According to Statistical Year Book, Iran 2011, its "urban dwellers" is 667499 (Iran Statistics Center 2011). Furthermore, in accordance for Uremia's Master Plan, it has four urban districts (Consultant Architects et al, 2011).

\subsection{Review of the Related Literature}

Regarding the establishment of electronic cities and their challenges ahead, many foreign and domestic researchers have carried out numerous studies. As it is not possible to mention the results of all studies done, some of them will be pointed out as examples:

Ergazakis (2011) has investigated decision-making methods for carrying out projects in a comprehensive, unified system in electronic cities (Ergazakis, E, 2011). Bailey and Ngwenyama (2011) have studied challenges in the way of electronic participation (E-participation) (Bailey A et al, 2011). Wu Fulong (2007) has done a research on the revitalization of urban development aspects and directions through new, technology-oriented strategic planning and design for Chinese cities (Wu F. 2007). Dennis, et al. (2011) has researched ICT network limitations in Suzhou Municipality, China (Dennis, W, Y, H silva, 2011). Mohammadi et al. (2013) have studied the most important challenges in the face of the establishment of electronic cities in the District 6 of the Metropolitan Isfahan, Iran. Rutherford (2009) has mentioned basic concepts regarding information cities in International Encyclopedia of Human Geography (Rutherford, j. 2009). Pazalos (2012) has presented a structured method for the evaluation and correction of electronic cities (Pazalos, K, 2012).

In a research titled "Thinking E-Cities: Twenty-First Century", Kentucky Science and 
Technology Council (2012) believes that electronic cities are the most significant strategies as a way out of urban challenges; and, in this regard, to achieve digital literacy and proficiency, software and hardware infrastructures should be reinforced and citizens' electronic education should be implemented (Kentucky Science et al, 2009).

In a paper titled "Identification of the Electronic City Application Obstacles in Iran", Asgharzadeh, et al. (2009) feel that the most important challenges of the establishment of electronic cities are lack of software and hardware infrastructures, lack of citizens' culture, behavior and education, lack of necessary investment and safety and legal obstacles (Asgharizadeh, E. M. et al, 2009).

Alizadeh, et al. (2014) have mentioned development of software and hardware infrastructures, promotion of digital literacy and proficiency, zeal of managers for uploading services on the portals of municipalities and other organizations related to urban affairs, investments of international and national firms, etc. as the most important factors effective on the establishment of electronic cities.

\section{Research Theoretical Foundations}

With reference to successful case studies, many urban policy makers and planners in different countries try to account for the fact that how urban development strategies can create positive changes in daily lives of citizens and reduce urban problems [34]. In this approach, the main aim is to provide urban sustainable development through creating social potentials for widening participative outlook and public action [24]. It seems what can realize analytical framework for urban performance from the viewpoint of urban development strategy that is, inclusive city, creative city, good governance and sustainable city is the establishment of electronic cities (Cities Alliance, 2008) for the creation of electronic cities will entail many influences on economic, social, cultural and political aspects of urban administration. The successful experiences of city development strategy in different cities (Sofia, Johannesburg, Eden, Delhi, etc.) can be good examples for the future development projects of Iranian cities with emphasis on different aspects of city development especial for each case because in Iranian projects of city development, the participation of public is nearly nothing in different stages, the relationship of the projects is low with economic, social, historical, geographical and physical comprehensive studies, realism in the goals and feasibility of projects is so low and the observance of justice in projects is so low (Hataminejad, H. et al, 2011). "What is achieved by urban planning?", "Do citizens benefit from urban planning?", "What role can citizens play in urban planning?" and especially, "How can the relationships and cooperation among different urban stakeholders be made use of?" New opportunities opened through ICT are considered as a key point in the contemporary theories of urban planning (Graham, S. et al, 1996).

Therefore, today, increasing development of network, knowledge-based and information societies is the common aim of many authorities all over the world. One of the driving forces of this kind of development is new ICT (Talvitie, Juha, 2004). Its quality and diversity in different aspects such as supporting the communications and interactions of citizens, communities and government authorities, reducing traffic congestion (Talvitie, Juha, 2004) 
augmenting the extent of citizens' participation, the establishment of tele-centers in providing access to electronic culture in divers parts of societies and ultimately the implementation of electronic cities (Kumar, R. et al, 2006) can be different. The second half of the $20^{\text {th }}$ century moves toward becoming small and small (in McLuhan words, toward global village). The mechanisms of Information Age are based on not only technologies resulted from industrial ages (productive technology), but also data processing and they come from the implication of ICT (Montazer, G. 2002).

The lack of guideline conceptual frameworks poses a challenge on the way of investigating ICT and urban planning. Graham and Marvin discusses that Instead of accepting dynamism of ICT and urban environments, many urban planning specialists is working in this field with traditional views on urban spaces[38].

To give an idea regarding challenges urban planning deals with, some studies have focused on special problems including the reactions of planning to changes in urban land use related to ICT. A McMahon (1999) explains, to take care of the new types of land use (such as industrial and commercial parks, telework centers) and the infrastructures of information technology requires changes in planning mechanisms and strategies, including "the revision of zoning ordinances" and/or the optimization of development investigation process (McMahon, K. 1999). The enactment of the revised Telecommunications Act of 1996 caused to pay attention to the relationship between the effects of information technology and local planning (Lawlor, V. N, 1999). Evans-Cowley and his colleagues have investigated the responds of USA metropolitans planning in facilities development and figured out that only few cities have formal policies in this regard; and, they suggest that through ICT infrastructure systems in a master plan, cities have better understanding of future probabilities of land use for the development of ICT infrastructures (Evans-Cowley, J. et al, 2003). The most important and most basic stage in the creation of electronic cities is to develop their strategic document. In the document, the perspectives, missions, projects and initial plans of the establishment of digital cities have been gathered (Jalali, A. 2005). Therefore, to improve the life quality of citizens requires moving toward web-based urban management or network management.

\section{Findings and Discussion}

\subsection{SWOT Technique}

SWOT technique is a tool that identifies opportunities and threats available in the external environment of a specified system and determines its internal strengths and weaknesses in order to evaluate the existent situation and develop strategies for controlling and leading that system. It is considered the best for organizations (Moradi Masihi, V. 2002). The technique is a tool for evaluating the existent situation and developing strategies. These are done through identifying and classifying any specified system's internal strengths and weaknesses, identifying and classifying its external threats and opportunities, completing SWOT matrix and compiling various strategies for leading the system in the future (Golkar, K. 2005). This

\footnotetext{
3 - SWOT stands for Strengths (S), Weaknesses (W), Opportunities (O) and Threats (T).
} 
technique evaluates system's effective and progressive factors (city, region, etc.) through grading each factor.

In SWOT table, columns are as following

Column 1 (external and internal factors): The most important strengths, weaknesses, opportunities and threats of any specified system are introduced.

Column 2 (weights): Based on above-mentioned factors' probable effects on the system's present strategic situation, weights from 1 (the most important) to 0 (the least important) are assigned to each factor. The more the weight, the more effective the factor on the system's present and future situation (total sum of column 2 is 1 regardless of number of factors).

Column 3 (grading): Based on the system's present situation and the importance of factors, grades from 5 (so strong) to 1 (weak) (according to the results obtained from the evaluation of urban affairs specialists) are assigned to each factor.

Column 4 (weighted grade): Each factors' weight is multiplied by its grade (column2 $\mathrm{x}$ column3) so that weighted grades may be achieved. For each factor, a weighted grade is assigned from 1 to 5 in that average value is 3 .

Ultimately, weighted grades of all external and internal factors are separately summed in column 4 and weighted grades are achieved. Total weighted grade shows how the system responds to its internal and external forces. The average total weighted grade in any specified system's special field is 3 (Hunger D. J. et al, 2002). If the amount is higher than 3 , the factor is more important and If the amount is lower than 3 , the factor is less important.

\subsection{Uremia's Electronic City Establishment External Factors Analysis Summary (EFAS)}

To organize external factors in the framework of threats and opportunities in the face of the system, making use of factor grading and the importance of each threat and opportunity, their effectiveness on Uremia's urban functions are calculated and shown in following tables.

Table 1. External Factors Analysis (Opportunities)

\begin{tabular}{|c|c|c|c|}
\hline Opportunities & Weights & Grades & $\begin{array}{l}\text { Weighted } \\
\text { Grades }\end{array}$ \\
\hline $\begin{array}{l}\text { Gradual formation of a new social generation for absorbing investments (creative } \\
\text { generation) }\end{array}$ & 0.09 & 5 & 0.45 \\
\hline Establishment of without-border city enjoying dynamic, knowledge-based economy & 0.08 & 5 & 0.40 \\
\hline Promotion of social justice regardless of citizens' religion, ethnicity, age and gender & 0.08 & 4 & 0.32 \\
\hline Establishment of unified urban management & 0.06 & 3 & 0.18 \\
\hline Protection of ecology and the establishment of sustainable city & 0.07 & 5 & 0.35 \\
\hline Establishment of social understanding and collaborative participation & 0.06 & 4 & 0.24 \\
\hline
\end{tabular}




\begin{tabular}{|l|r|r|r|}
\hline Changes in life style and dynamic presence in globally financial networks and & \multirow{2}{*}{0.08} & 4 & 0.32 \\
currents & & 0.52 & - \\
\hline TOTAL & 2.26 \\
\hline
\end{tabular}

According to the table, the most important opportunities of Uremia in the establishment of an electronic city from the viewpoint of urban specialists include: gradual formation of a new social generation for absorbing investments (creative generation) with weighted grade of 0.45 as the first opportunity, establishment of without-border city enjoying dynamic, knowledge-based economy with weighted grade of 0.40 as the second opportunity, protection of ecology and the establishment of sustainable city with weighted grade of 0.35 as the third opportunity, promotion of social justice regardless of citizens' religion, ethnicity, age and gender with weighted grade of 0.32 as the fourth opportunity.

Table 2. External Factors Analysis (Threats)

\begin{tabular}{|c|c|c|c|}
\hline Threats & Weights & Grades & $\begin{array}{l}\text { Weighted } \\
\text { Grades }\end{array}$ \\
\hline Lack of identical distribution of ICT indexes among Uremia's districts & 0.06 & 4 & 0.24 \\
\hline $\begin{array}{l}\text { Lack of a specified strategy (strategic document) for Uremia's future development and } \\
\text { lack of attention to global experience in this regard }\end{array}$ & 0.09 & 5 & 0.45 \\
\hline $\begin{array}{l}\text { Uremia's horizontal development and sprawl development against vertical development } \\
\text { and infill development }\end{array}$ & 0.07 & 3 & 0.21 \\
\hline Parallel extra working wasted double working in Uremia's urban development process & 0.05 & 5 & 0.25 \\
\hline Security-oriented look into data flow & 0.08 & 5 & 0.40 \\
\hline $\begin{array}{l}\text { Reinforcement of traditional urban management, bureaucracy, personal refers and high } \\
\text { congestion of citizens in public organizations, institutes and bodies }\end{array}$ & 0.04 & 3 & 0.12 \\
\hline High-cost and low-speed internet & 0.09 & 4 & 0.36 \\
\hline TOTAL & 0.48 & - & 2.03 \\
\hline
\end{tabular}

However, according to the table 2, the most important threats of Uremia in the establishment of an electronic city from the viewpoint of urban specialists respectively include: Lack of a specified strategy (strategic document) for future development) with weighted grade of 0.45 , security-oriented look into data flow with weighted grade of 0.40 , High-cost and low-speed internet with weighted grade of 0.36 . 


\section{Ml Macrothink}

Environmental Management and Sustainable Development

ISSN 2164-7682

2015, Vol. 4, No. 2

\subsection{Uremia's Electronic City Establishment Internal Factors Analysis Summary (IFAS)}

To organize internal factors in the framework of strengths and weaknesses in the face of the system, making use of factor grading and the importance of each threat and opportunity, their effectiveness on Uremia's urban functions are calculated and shown in following tables.

Table 3. Internal Factors Analysis (Strengths)

\begin{tabular}{|c|c|c|c|}
\hline Strengths & Weights & Grades & $\begin{array}{l}\text { Weighted } \\
\text { Grades }\end{array}$ \\
\hline $\begin{array}{l}\text { All citizens' access to telephone, cell phone, telephone kiosks, and ICT offices all over } \\
\text { the city }\end{array}$ & 0.05 & 4 & 0.20 \\
\hline Access of over than three quarters of urban households to computers & 0.04 & 5 & 0.20 \\
\hline Available regulations regarding cybercrimes & 0.09 & 5 & 0.45 \\
\hline Inclination of Uremia urban specialists toward the implementation of electronic city & 0.07 & 5 & 0.35 \\
\hline Uremia's population over than 600,000 & 0.05 & 3 & 0.15 \\
\hline Citizens' desire for access to single-stage services & 0.08 & 3 & 0.24 \\
\hline Meetings and conferences held on electronic cities all over the city & 0.05 & 2 & 0.10 \\
\hline Creation of some ground for electronic commerce development & 0.06 & 4 & 0.24 \\
\hline $\begin{array}{l}\text { Installation of electronic systems for organizations, universities, terminals, airports } \\
\text { and so on. }\end{array}$ & 0.06 & 5 & 0.30 \\
\hline TOTAL & 0.55 & - & 2.23 \\
\hline
\end{tabular}

According to table 4, lack of digital literacy and proficiency among citizens with weighted grade of 0.45 , local and international companies' lack of desire for investment with weighted grade of 0.32 , carbon and industrial economy dominant on Uremia and ignorance of knowledge dominancy with weighted grade of 0.30 are among the most important weaknesses in the face of the establishment of electronic city in Uremia.

Table 4. Internal Factors Analysis (Weaknesses)

\begin{tabular}{|l|c|c|c|}
\hline \multicolumn{1}{|c|}{ Weaknesses } & Weights & Grades & Weighted \\
\hline Lack of digital literacy and proficiency among citizens & & Grades \\
\hline Local and international companies' lack of desire for investment & 0.09 & 5 & 0.45 \\
\hline Lack of urban managers' desire for uploading services on portals & 0.08 & 4 & 0.32 \\
\hline
\end{tabular}




\begin{tabular}{|l|c|c|c|}
\hline Lack of citizens' participation in urban projects & 0.07 & 4 & 0.28 \\
\hline Invasion to others' privacy & 0.05 & 3 & 0.15 \\
\hline Lack of citizens' belief in cyber spaces & 0.05 & 2 & 0.10 \\
\hline Carbon and industrial economy dominant on Uremia and ignorance of & 0.06 & 5 & 0.30 \\
knowledge dominancy & 0.45 & - & 1.85 \\
\hline TOTAL & & & \\
\hline
\end{tabular}

\subsection{Strategic Factors Analysis Summary (SFAS)}

Using IFAS and EFAS tables and combining their results, the most significant strategic factors in the establishment of Uremia's electronic city have been presented. In fact, analyzing strategic factors, planners making strategic decisions limit strengths, weaknesses, opportunities and threats to lesser numbers. This has been carried out through the reinvestigation of available factors in IFAS and EFAS tables. Actually, the most weighted factors of those tables should be included in SFAS table. One can see the above mentioned points in the following table:

Table 5. Strategic Factors analysis Summary regarding The Establishment of Electronic City

\begin{tabular}{|c|c|c|c|c|c|c|c|}
\hline & & & & & & Planning & \\
\hline & Strategic Factors & Weight & Grading & Grade & $\begin{array}{l}\text { Short } \\
\text { Term }\end{array}$ & $\begin{array}{l}\text { Medium } \\
\text { Term }\end{array}$ & $\begin{array}{l}\text { Long } \\
\text { Term }\end{array}$ \\
\hline & $\begin{array}{l}\text { S1 available regulations regarding } \\
\text { cybercrimes }\end{array}$ & 0.09 & 5 & 0.45 & $*$ & & * \\
\hline $\begin{array}{c}\text { Internal } \\
\text { Opportunities }\end{array}$ & $\begin{array}{l}\text { S2 inclination of Uremia urban } \\
\text { specialists toward the } \\
\text { implementation of electronic city }\end{array}$ & 0.07 & 5 & 0.35 & & * & * \\
\hline & $\begin{array}{l}\text { S3 installation of electronic systems } \\
\text { for organizations, universities, } \\
\text { terminals, airports }\end{array}$ & 0.06 & 5 & 0.30 & & $*$ & $*$ \\
\hline Internal Threats & $\begin{array}{l}\text { W1 lack of digital literacy and } \\
\text { proficiency among citizens }\end{array}$ & 0.09 & 5 & 0.45 & * & & $*$ \\
\hline (W) & $\begin{array}{l}\text { W2 lack of urban managers' desire } \\
\text { for uploading services on portals }\end{array}$ & 0.08 & 4 & 0.32 & $*$ & & $*$ \\
\hline
\end{tabular}




\begin{tabular}{|c|c|c|c|c|c|c|c|}
\hline & $\begin{array}{l}\text { W3 carbon and industrial economy } \\
\text { and ignorance of knowledge } \\
\text { dominancy }\end{array}$ & 0.06 & 5 & 0.30 & $*$ & & * \\
\hline & $\begin{array}{l}\text { W4 lack of urban managers' desire } \\
\text { for uploading services on portals }\end{array}$ & 0.05 & 5 & 0.25 & $*$ & & * \\
\hline \multirow[t]{3}{*}{$\begin{array}{l}\text { External } \\
\text { Opportunities } \\
\text { (O) }\end{array}$} & $\begin{array}{l}\text { O1 gradual formation of a new social } \\
\text { generation for absorbing investments } \\
\text { (creative generation) }\end{array}$ & 0.09 & 5 & 0.45 & & $*$ & * \\
\hline & $\begin{array}{l}\text { O2 establishment of without-border } \\
\text { city enjoying dynamic, } \\
\text { knowledge-based economy }\end{array}$ & 0.08 & 5 & 0.40 & & $*$ & * \\
\hline & $\begin{array}{l}\text { O3 protection of ecology and the } \\
\text { establishment of sustainable city }\end{array}$ & 0.07 & 5 & 0.35 & & $*$ & * \\
\hline \multirow[t]{3}{*}{ External Threats } & $\begin{array}{l}\text { T1 lack of a specified strategy } \\
\text { (strategic document) for Uremia's } \\
\text { future development }\end{array}$ & 0.09 & 5 & 0.45 & $*$ & & * \\
\hline & $\begin{array}{l}\text { T2 security-oriented look into data } \\
\text { flow }\end{array}$ & 0.08 & 5 & 0.40 & $*$ & & * \\
\hline & T3 low-speed, high-cost internet & 0.09 & 4 & 0.36 & * & & * \\
\hline
\end{tabular}

Putting all factors together, different offensive (SO), diversity (ST), review (WO) and defensive (WT) strategies have been developed.

\section{Developing Strategies}

\section{a) Offensive Strategies (SO)}

- Preparing necessary plans regarding tackling space and time barriers so that citizens can have easy access to urban facilities and services and presenting national organized plan or project.

- Developing and/or promoting ICT infrastructures and facilities in Uremia's four districts proportionate to their population and avoiding digital divide(s) among citizens.

- Defining composite land uses in the city.

- Avoiding the city's irregular physical development and paying attention to urban infill 
development.

- Exploiting global experiences on the establishment and development of electronic cities including Vienna, Tokyo, Zurich and Munich.

- Employing managers and expert specialized in the establishment of electronic cities.

\section{b) Diversity Strategies (ST):}

- Developing a specified strategy, that is, strategic document for the establishment of electronic city in Uremia.

- Assigning a specified organization or institute as main responsible for establishing electronic city.

- Allowing all citizens to have access to needed data and avoiding having security point of view.

- promoting high-speed internet with low costs.

- taking necessary measures regarding environment protection including car usage reduction, bureaucracy reduction, efficient energy consumption, etc.

\section{c) Review Strategies (WO)}

- Paving way for the investments of public and private sectors in the establishment of projects of electronic city

- Paying special attention to knowledge-based economy and elites in this regard.

- Holding necessary workshops for citizens and encouraging their participation in urban projects and plans.

- Respecting people's privacy

- Promoting the average level of public education, the proper information of mass media regarding electronic city and digital literacy.

\section{b) Defensive Strategies (WT)}

- Developing laws and regulations on the promotion and correction of managerial entities, employing knowledgeable managers in the different departments of developing electronic cities and promoting management stability in this regard.

- Paying attention to electronic municipality and electronic citizens as the necessary ground for the establishment of electronic cities.

- Training efficient and expert work forces for managing electronic cities.

- Promoting electronic exchanges and different integrated systems (educational, medical, managerial-institutional and so on) in Uremia.

- Removing political and cultural barriers through transforming administrative system to 


\section{Macrothink}

efficient, flexible, transparent, decentralized, democratic and legal administrative system and supporting content production.

Enacting proper regulations regarding electronic money transfer, cybercrimes, intellectual property, information free flow and electronic signature.

Investigation of global electronic cities including Vienna, Tokyo, Zurich, Amsterdam, and Helsinki indicates that most of those cities have developed electronic cities through developing strategic master plans or strategic documents. Total conditions of Electronic cities' conceptual-administrative models show the emphasis on promoting urban infrastructures in integrated exchanges of electronic municipalities. Those conditions are applicable in Iranian cities. Electronic city is organic integration of systems. And, the interrelationship between a smart city's core systems is taken into account to make the system of systems smarter. No system operates in isolation. Therefore, if one wants to implement an electronic city in Iran, one should reinforce interactions among organizations and their departments because obvious matters in Iranian cities include lack of a proper strategy for urban development, subjective urban management, numerous decision making centers in urban management, ignorance of specialty and knowledge dominancy or web-based management, ignorance of global experiences and so on. Those result in the fact that citizens increasingly fulfill their requests by referring to public offices including municipalities, bureaucracy increases, the rights of people with disabilities are ignored in urban affairs, inequalities increase and so on. A conceptual model for the establishment of electronic cities is shown in figure 1. 


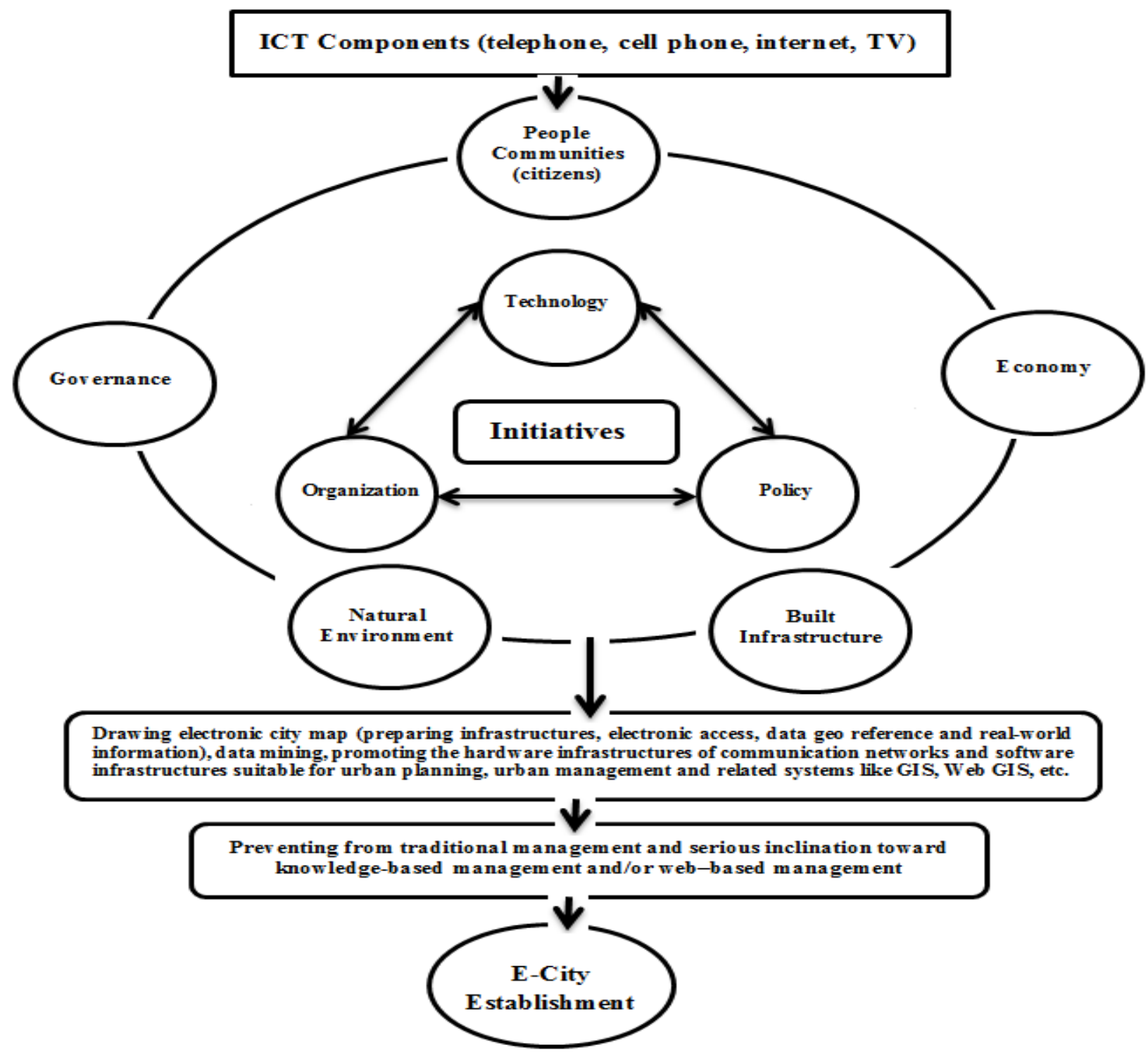

Figure 1. Presentation of a Conceptual Model for the Establishment of Electronic Cities

Reference: Findings of the study presented here with reliance on global experiences and their comparison to urban management methods in Iran, 2014

\section{Concluding Remarks}

Obviously, today, it is not possible to manage cities, generally, and metropolitans, especially, based on traditional methods. This requires a transition from traditional planning to electronic planning. This kind of management method is able to assist urban managers in delivering proper services to citizens and improving life quality in cities. Therefore, to have creative, knowledge-based and efficient cities in the future requires paving way for establishing electronic cities. . Findings indicate that the most important challenges in the way of establishing an electronic city include the lack of strategic document for urban development, high number of decision-making centers and administrative parallelism among them, the inclination of the urban managers toward traditional methods, low-speed, high-cost internet 
connection, the lack of infrastructures for ICT, the lack of digital literacy among citizens, all of which need short-term, medium-term, long-term planning, absorbed attention in the current study.

\section{References}

Ahadi, H. R., Ghasemi Sahebi, M., \& Zakeri, J. A. (2013). The Prioritization of Public Transportation Methods in Tehran for Correcting Budget Allocation System. Transportation Engineering Quarterly, 4(3).

Alipoor, M. A. (2003). An Smart System for Controlling Urban Traffic Using Factors. Unpublished MA Thesis. Tehran Teacher Training University: Technical and Engineering Department.

Alizadeh, J., Zarrabi, A., \& Taghvi. M. (2014). An Evaluation of Factors Effective on the Establishment of Uremia's Electronic City. Urban and Regional Logistics Scientific and Research Quarterly of Zahedan University.

Asgharizadeh, E. M. Ajalli Geshlajoughi, \& S. R. Safavi Mirmahalleh. (2009). Identification of the Electronic City Application Obstacles in Iran, International Journal of Human and Social Sciences, 4(3), 2009

Bailey A, Ngwenyama O. (2011). The challenge of e-participation in the digital city exploring generational influences among community telecentre users. Telematics and informatics, $28(3)$

Bakhtiari, S., \& Dehghanizadeh, M. (2013). The Role of Industrial Activities in the Economic Development of Input-Output Model in Urban Regions. Budget Planning Quarterly, 18(2).

Chen, Jie. (2007). Rapid urbanization in China: A real challenge to soil protection and food security, www.elsevier.com/locate/catena Catena, 69(2007), 1-15.

Cities Alliance (2008). Guide City Development strategies, UNCHS (Habitat).

Consultant Architects and Town Planners. (2011), Uremia Master Plan, Uremia: Uremia Municipality.

Dennis, W, Y, H silva, (2011). Network configurations and R/ D activities of the ICT industry in Suzhou municipality, China geoforum 42(4).

Ergazakis, E, (2011). Digital cities: towards an integrated decision support methodology, Telematics and informatics, 28(3).

Evans-Cowley, J., Malecki, E. J., \& McIntee A. (2003), Planning responses to telecom hotels : what accounts for increased regulation of colocation facilities? Journal of Urban Technology.

Golkar, K. (2005). Adaptation of SWOT Technique for Applications in Urban Design. Soffeh Journal 15(41).

Graham, S., \& Marvin, S. (1996), Telecommunications and the City: Electronic Spaces, Urban Places. London: Routledge. 
Hanley, Daniel. (2003). Cockburn Community Development Sstrategy, p:24, (Internet:http: // www.citiesalliance.org/publication/otherresources/other resources.CDS.html).

Hataminejad, H., \& Faraji Mollayi, A. (2011). The Feasibility of Strategic Projects of Urban Development in Iran. Urban and Regional Studies, 2(8).

Hosseinzadeh Delir, K., Sadr Musavi, S., Heidari, R., \& Rezataba'a, Kh. (2011). An Introduction to New Urban development Strategy in Urban Planning Process with Emphasis on Challenges Emerged for Master Plans in Iran. Geographical Space Research Scientific Quarterly, 11(36).

Hunger D. J., \& Wheelen, T. (2002). Essentials of Strategic Management. (Izadi D. \& Aarabi, M). Tehran: Cultural Studies Office Publications.

Iran Statistics Center (2011). West Azerbaijan Statistical Year Book, Tehran.

Jalali, A. (2005). Electronic City. Iran University of Science and Technology Publications.

Kentucky Science and Technology Council. (2009). E-Cities: twenty-first century thinking, kris kimel at kentucky science and technology corporation h po box 1049, lexington, ky 40588h, org h phone/606.233.3502 h fax/606.259.0986h www.kstc.org.

Kumar, R., \& Best, M. L., (2006). Impact and sustainability of E-government services in developing countries: lessons learned from Tamil Nadu, India. The Information Society, 22(1), $1-12$.

Ladan, A., \& Rezghi, H. (2009). Reasons of Formation of Shanty Town areas in the Great Tehran. Urban Management Studies, 1(3).

Lawlor, V. N, (1999). Cities and Urban Life. Upper Saddle River, NJ :Prentice Hall.

McMahon, K. (1999). Smart and smarter Planning, Journal of urban studies 65(7).

Mohammadi, J., Zarrabi, A., Alizadeh Asl, J., \& Samsam Shariat, J. (2013). An Analysis of ICT Assessment and Its Role in the Establishment of Social Participation and Urban Management Empowerment (Case Study: Isfahan District 6). Urban Management Quarterly, No. 31 .

Montazer, G. (2002). IT-Oriented Development as a Basis for Futurism in Iranian Educational System. Higher Education Planning and Research Quarterly, No. 25.

Moradi Masihi, V. (2002). Strategic Planning in Metropolitans. Tehran: Urban Process and Planning Publications.

Pazalos, K. (2012). A structured methodology for assessing and improving e - services in digital cities, Telematics and informatics, 29(1).

Rezwan, A., and Fathi, M. (2012). An Investigation of Factors Related to Feeling of Insecurity in Urban Neighborhoods of Tehran District 3. Social Welfare Research Scientific Quarterly, 12(45). 
Rutherford, J. (2009), Informational city, international encyclopedia of human geography, Elsevier press.

Sadeghi, H., \& Saadat, R. (2004). Population Growth, Economic Growth and Ecological Consequences in Iran. Economic Studies, No. 64.

Sadeghi, R., Belali, E. \& Mohammadpour, A. (2010). Social Inequality in Passing Lesiure Time. Social Welfare Quarterly, 10(39).

Safdarzadeh, Z. (2013). The Extent of Conformity of Urban Passages to the Needs of People with Disabilities (Case Study: Shirwan, Iran), Zagros Landscape Geography and Planning Quarterly, 5(15).

Shiyani, M., Razavi-al-Hashem, B., \& Delpasand, K. (2012). An Investigation of Social Factors Effective on Citizens' Participation in the Management of Urban Affairs in Tehran. Urban Studies Quarterly, 2(4).

Silva, Carlos Nunes, (2010). The E-Planning Paradigm-Theory, Methods and Tools: An Overview, Institute of Geography and Spatial Planning, University of Lisbon, Portugal.

Statistical Year Book. (2011). Iranian People and Housing Census Calendar, Tehran.

Taghvaei, M., Babanasab, R., \& Musavi, C. (2010). An Analysis of ICT Condition and Its Role in Urban Management and Planning (Case Study: Nadjaf Abad, Isfahan). Geography and Planning Journal, 15(31).

Tai-Chee Wong \& Belinda Yuen, (2011). Eco-city Planning Policies, Practice and Design, Springer Dordrecht Heidelberg London New York ISBN 978-94-007-0382-7.

Talvitie, Juha. (2004), Incorporating the Impact of ICT into Urban and Regional Planning, EuropeanJournal of Spatial Development-http://www.nordregio.se/EJSD/-ISSN 1650-9544-Refereed Articles Sep 2004- no10.

United Nations. (2006). World Urbanization Prospects the 2005 Revision Executive Summary Fact Sheets Data Tables, United Nations New York.

United Nations. (2008). united nations expert group meeting on population distribution, urbanization, internal migration and development, Department of Economicand Social Affairs Population Division New York, 21-23 January.

Varesi, H., Beikmohammadi, H., \& Akbari, M. (2011). Spatial Analysis and Planning of Deficits of Yasuj Urban Service Centers. Geographical Studies Quarterly, 25(100).

Wu F. (2007). Re- orientation of the city plan: strategic planning ad design competition in china, geoforum.

Yusefi, A., \& Varshoei S. (2011). Social Inequality in Mashhad Urban Space. An Estimation of Education and Income Inequalities in Urban Spaces, 4(4).

Zahedi, Sh., Mohammad Nabi, S., \& Shahbazi, M. (2009). An Investigation of Factors Effective on the Reduction of Bureaucratic Corruption (Case Study of Tehran Municipality, 


\section{Macrothink \\ Environmental Management and Sustainable Development \\ ISSN 2164-7682 \\ 2015, Vol. 4, No. 2}

Iran). Organizational Culture Management Journal, 7(20).

Zarrabi, A., \& Musavi, N. (2010). The Spatial Analysis of Population Distribution and Services Dispersion in Yazd Urban Districts. Geographical Studies Quarterly, 25(2).

Zarrabi, A., Mohammadi, J., \& Alizadeh Asl, J. (2011). An Analysis of ICT Assessment and Its Role in Urban Planning and Management (Case Study: Central Area of Isfahan, Iran). Geography and Planning Scientific Journal of Tabriz University, 16(37).

\section{Copyright Disclaimer}

Copyright for this article is retained by the author(s), with first publication rights granted to the journal.

This is an open-access article distributed under the terms and conditions of the Creative Commons Attribution license (http://creativecommons.org/licenses/by/3.0/). 